\title{
Percepção de estudantes e professores universitários sobre a profissão do contador: um estudo baseado na teoria dos Estereótipos
}

\begin{abstract}
Resumo
Pesquisas apontam que o profissional da Contabilidade é o que tem se preocupado mais nos últimos anos com a imagem pública e que uma compreensão das imagens externas dos contadores é importante para o julgamento dos papéis desses em um contexto social mais amplo. O estudo buscou identificar e analisar a percepção da imagem da atividade profissional do contador pelos estudantes e professores de cinco cursos de graduação. As opiniões declaradas apontam como uma carreira desinteressante, envolvendo atividades repetitivas, que cumpre normas e envolve muitos cálculos, além do que o próprio profissional vem sendo visto como introspectivo, pouco crítico e comunicativo. O contador é visto como um profissional sem visão de negócios, pouco participativo ou envolvido na gestão e pouco atualizado; usa muito a lógica e se esquece das pessoas; apenas cumpre normas e resolve questões operacionais. Quanto à profissão em si, é percebida envolvendo cálculos e matemática e ligada a aspectos fiscais e tributários, principalmente à declaração do Imposto de Renda. Portanto, não há como negar que existe uma percepção estereotipada sobre esse profissional, pois o contador ainda está ligado à imagem do guarda-livros, atrelado somente às exigências fiscais.
\end{abstract}

Palavras-chave: estereótipo; percepção; contador.

\section{Karla Splitter}

Mestrado em Contabilidade (UFSC).

Contato: Rua 3.300, n. 108, apto. 602.

Centro. Balneário Camboriú, SC, Brasil,

CEP.: 88330-272.

E-mail: ksplitter@yahoo.com.br

\section{José Alonso Borba}

Doutorado em Contabilidade (USP), Docente pela Universidade Federal de Santa Catarina (UFSC). Contato: Campus Universitário PPGC, Trindade, Florianópolis, SC, CEP: 88040-970.

E-mail: jalonso@ufsc.cse.br 


\section{Introdução}

Algumas profissões conseguiram criar uma boa imagem perante a sociedade ao longo do tempo, solidificando sua imagem pública. Outras, no entanto, padecem no tocante à criação de uma imagem profissional sólida e respeitável. Esse é o caso da profissão do contador. Para Belski, Richmond e Brozovsky (2004), o sucesso dessa profissão depende amplamente de como a profissão é vista pelo público, principalmente por ela ter sido abalada no passado recente pela ampla publicidade de fraudes, escândalos e falências envolvendo esses profissionais. Além do mais, Albrecht e Sack (2000) ainda descrevem outros entraves relacionados à imagem dessa profissão, como as mudanças no ambiente empresarial, diminuição dos níveis de salário na profissão, o aparecimento de outras carreiras como alternativas mais atraentes aos estudantes e a falta de informação e/ou desentendimento sobre a carreira de Contabilidade.

Para Dimnik e Felton (2006), o contador é uns dos profissionais que mais tem se preocupado, nos últimos anos, com a imagem pública. Os autores colocam que, durante anos, os contadores vêm sofrendo com a imagem de uma pessoa chata, pouco atraente, forçados a se defender contra acusações de irrelevância, esforçando-se para reforçar sua reputação de competente e íntegro. Azevedo (2010) menciona que a percepção pública sobre a Contabilidade é fonte de preocupação para o profissional da Contabilidade, principalmente, por ser considerada equivocada e estereotipada. Morais (2007) comenta que essa preocupação influencia muitos profissionais, que acabam incorporando tal sentimento de descrédito e buscam outras profissões nas quais possam se sentir mais valorizados.

As percepções negativas da Contabilidade e dos contadores se originam com as argumentações de Stacey (1958), que afirma que a imagem do contador como retratada em romances, poesia e drama não é muito lisonjeira. Desde então muitas pesquisas internacionais foram realizadas para identificar o estereótipo do contador e da própria Contabilidade. Imada, Fletcher e Dalessio (1980) reexaminam os estereótipos do contador com entrevistadores da área, contadores e estudantes britânicos. Os resultados indicam que os alunos percebem o contador como mais interessado em gestão de negócios, atividades que envolvam trabalho detalhado e baixo nível de desgaste, enquanto entrevistadores e contadores percebem como aventureiro, extrovertido, vasta gama de interesses. Fischer e Murphy (1995) relatam a percepção de grupos de Contabilidade e estudantes de outros cursos sobre o estereótipo do contador. Estudantes que não cursam Contabilidade demonstraram antipatia pela profissão, considerando-a tediosa, que causa aborrecimentos e forte sugestão de práticas antiéticas. Os alunos de Contabilidade, por sua vez, reconhecem as atitudes negativas em relação à profissão, contudo estão comprometidos com a carreira e acreditam que Contabilidade é algo interessante de se estudar; entendem que a profissão tem status elevado. A pesquisa de Michael e Levas (2003) apontam que os estudantes de outros cursos na área de negócios interpretam o estereótipo do contador como conservador, retraído e com dificuldades de trabalho em grupo.

No cenário nacional, Azevedo, Cornachione Júnior e Casa Nova (2008) compararam as percepções dos alunos de Contabilidade com outros cursos. O estudo identificou diferenças significativas relativamente à percepção que se tem sobre o curso de Contabilidade para os fatores relativos à ambição, propensão ao risco, independência, orientação a pessoas, nível de estudo, trabalho em equipe, flexibilidade, nível de estudo, liderança, sendo que, para esses fatores, a percepção dos estudantes dos outros cursos foi significativamente mais negativa do que a percepção dos estudantes de Contabilidade. Miranda, Miranda e Araújo (2012) analisaram as percepções de alunos do ensino médio sobre a atividade profissional do contador. Resultados apontam que os alunos não conhecem alguns aspectos relevantes da profissão; contadores foram considerados éticos; não há grande desvalorização da profissão comparada com outras.

O que as pesquisas demonstram é que um dos principais motivos dessas percepções equivocadas, ou até mesmo estereotipadas, é a falta de clareza sobre o que é a profissão e quais são as atividades exercidas pelo profissional da Contabilidade (Cobbs, 1976; Hazell, 1998; Parker, 2000; Smith \& Briggs, 1999). Se, em parte, a forma como as pessoas são vistas determina como elas são tratadas, supõe-se que as percepções dos contadores ou da própria Contabilidade são influenciadas pela ausência de informações. McMurdy (1997) acredita que a linguagem utilizada por contadores é uma forma de confundir o público e mantê-lo 
no escuro sobre o que é Contabilidade, contribuindo para a permanência dessas percepções equivocadas. Bougen (1994) segue nessa mesma linha, afirmando que essa percepção negativa é duradoura devido à complexidade da imagem do contador, que é derivada da interdependência entre a Contabilidade e a escrita fiscal e a indefinição das características pessoais e de Contabilidade em si.

A falta de nitidez das funções do contador e da própria Contabilidade faz com que os estudantes tenham uma imagem que não revela propriamente a realidade (Parker, 2000; Smith \& Briggs, 1999). Hiroshi (1998) comenta que outras disciplinas, como Medicina, Economia, Engenharia e Química, conseguem chamar a atenção para suas áreas, mostrando seus novos "produtos", suas curiosidades, ao contrário do que acontece em Contabilidade. Wells (2010) coloca que dessa forma a Contabilidade pode deixar de atrair as pessoas com habilidades e capacidades necessárias para a profissão.

Holland (1973) ressalta ainda, que são os estereótipos profissionais que formam a base para as decisões sobre qual carreira o indivíduo deve seguir. Portanto, "se esta visão é estereotipada negativamente pelos estudantes, pode acarretar na decisão precipitada de cursar outra formação em carreiras relacionadas, ao desconsiderar simplesmente a possibilidade de cursar Contabilidade" (Azevedo, 2010, p. 7). Os estereótipos acabam afetando, sobremaneira, a escolha da futura carreira profissional (Albu, Albu \& Girmina; 2011). Além disso, a existência de estereótipos já nos cursos frequentados pelos estudantes pode interferir, de maneira significativa, em sua atuação como futuros profissionais (Schlee, Curren, Harich \& Kiesler; 2007).

Nesse sentido, esta pesquisa tem o objetivo de identificar a percepção de alunos e professores universitários quanto às características desse profissional e funções desempenhadas. Portanto, a presente pesquisa propõe-se a buscar a resposta para o seguinte problema: Qual a percepção de estudantes e professores universitários acerca da profissão contábil?

Para Vicente e Machado (2010), a credibilidade e o desenvolvimento futuro da profissão contábil dependem da correspondente imagem pública, portanto uma percepção equivocada e estereotipada negativamente pelo público em relação à Contabilidade é prejudicial para o valor da profissão. É sabido que, a fim de atrair e reter os mais competentes e talentosos estudantes e profissionais, a profissão contábil carece de projetar uma imagem de confiança, respeitabilidade e de oferecer desafios (Azevedo, 2010).

Ainda para Azevedo (2010, p. 13), "se as pessoas não percebem a área de Contabilidade como uma área que proporciona desafios para o desenvolvimento de habilidades e aprendizados, estas muito provavelmente evitarão obter esse tipo de formação". Constata-se então que, para buscar criar uma boa imagem perante a sociedade, é necessária a divulgação das capacidades e potencialidades do profissional contábil. A falta de informação ou desinformação sobre o que é Contabilidade e o questionamento sobre qual é o papel dos contadores fazem com a que a Contabilidade continue sendo um mistério para muitos (Wells, 2010), o que pode contribuir para as percepções negativas do contador e da própria Contabilidade.

As consequências de uma percepção equivocada e estereotipada negativamente podem ocasionar prejuízos para o desenvolvimento de qualquer profissão, inclusive em relação ao próprio posicionamento na sociedade como profissional (Schlle et al.; 2007). Azevedo (2010, p. 14) coloca que, "quando os estereótipos inibem a capacidade da profissão de representar fielmente seus membros e de atrair novos estudantes, torna-se necessário entender e combatê-los". Nessa perspectiva, é preciso aprofundar os estudos sobre estereótipos tanto da Contabilidade quanto do profissional que a exerce.

\section{Revisão da Literatura}

\subsection{Estereótipos}

Os estereótipos surgem do processo cognitivo de formar percepções sobre grupos de pessoas, normalmente envolvendo a atribuição de rótulos para esses grupos. Esses rótulos são chamados "estereótipos". Assim, estereótipo seria, de forma simples, a ideia sobre algo ou alguém; a imagem espontânea que surge na mente quando o indivíduo se depara com determinadas situações. 
No sentido etimológico, o termo estereótipo tem origem grega, em que stereos significa "rígido", e túpos significa "traço". Inicialmente, o termo foi utilizado como jargão tipográfico, referindo-se a um molde metálico, com caracteres fixos, utilizado para produzir uma mesma impressão milhares de vezes (Azevedo, 2010; Pereira, 2002).

Walter Lippmann foi um dos primeiros estudiosos a utilizar o termo na área das ciências sociais, em seu livro “Public Opinion" em 1922. Para Lippmann (1922), estereótipos são imagens armazenadas na mente, detidas por indivíduos sobre objetos e pessoas de outros grupos. O autor menciona que os estereótipos surgem pela necessidade de simplificar o mundo, torná-lo mais compreensível do que realmente é, constituindo generalizações, nem sempre corretas, sobre eventos, grupos e categorias de pessoas. Dessa forma, os estereótipos servem como mecanismo de categorização, armazenando dados sobre o item categorizado para posterior utilização.

A definição de Lippmann foi utilizada como referência até 1933, quando da publicação do trabalho de Katz e Braly (Pereira, 2002), o qual se caracterizou como o primeiro estudo de natureza empírica sobre o assunto e, para tanto, 100 estudantes universitários americanos foram convidados a indicar os traços mais característicos de dez diferentes grupos sociais. O resultado foi a apresentação de um alto nível de consenso sobre as características de determinados grupos raciais e étnicos, como negros e judeus.

Pereira (2002) menciona que a definição do termo "estereótipo" sofreu várias alterações desde seu surgimento nas ciências sociais. Para o autor, apenas nos anos 80 , de fato, os estereótipos foram definidos dentro de uma abordagem cognitivista, quando Hamilton e Trolier (1986) definiram que os estereótipos são estruturas cognitivas que contêm os conhecimentos, as crenças e expectativas percebidas sobre um grupo social humano.

Na década de 90, os estereótipos passaram a ser considerados crenças compartilhadas referentes aos atributos pessoais, especialmente a traços de personalidade e a comportamentos de um grupo de pessoas (Leyens, Yzerbyt \& Schadron; 1994). Já na última década, Myers (2000) definiu estereótipos como crenças e percepções sobre atributos de um grupo, que, além das informações sobre esses atributos, apresenta também a extensão com que são compartilhados.

Os estereótipos mais comuns estão relacionados a aspectos raciais, culturais, de sexo e observações de determinados grupos de pessoas. Podem-se citar alguns exemplos de estereótipos culturais e raciais: "todos os árabes e mulçumanos são terroristas", "todos os judeus são gananciosos", "todos os africanos são bons na prática de esportes". Em relação ao sexo, pode-se citar: "os homens são mais fortes que as mulheres", "as mulheres não podem fazer um bom trabalho como um homem", "as meninas não são boas em esportes". Em relação aos estereótipos de determinados grupos, têm-se os exemplos: "as loiras são pouco inteligentes", "as crianças não gostam de comida saudável", "todos os góticos usam roupa preta, maquiagem preta e são deprimidos", "todos os bibliotecários são mulheres, usam óculos, amarram o cabelo em formato de coque", "as pessoas acima do peso são mais alegres".

Mas, por que categorizar as pessoas em grupos? Existem vários motivos, de acordo com os pesquisadores. Maximiano (2004, p. 255) coloca que "Como a percepção de outros é complexa, a simplificação é um recurso por meio do qual apenas uns poucos traços do comportamento alheio são percebidos." Assim, os estereótipos ocorrem quando utilizamos a nossa percepção sobre um grupo ou contexto para generalizar julgamentos em torno de indivíduos (Robbins, 2005), reduzindo a necessidade de cada indivíduo ser considerado separadamente. Tajfel e Turner (1986) ainda sugerem que a categorização em grupos permite que os indivíduos possam construir uma imagem superior de seu próprio grupo social e aumentar a sua própria autoestima, ou seja, as pessoas tendem a avaliar as pessoas de seu grupo de uma forma mais positiva em relação àquelas que não pertencem ao grupo.

Para Macrae, Milne, e Bodenhausen (1994), a motivação para o estereótipo está no desejo de conservar os recursos mentais e surge devido à carga de informação cada vez maior com que os indivíduos estão lidando. Para os autores (1994, p. 37), os “estereótipos, portanto, servem para simplificar a percepção, julgamento e ação. [...] poupam os percebedores a provação de responder quase incompreensivelmente a um mundo social complexo." 
A formação e a forma como são organizados os estereótipos podem ocorrer por múltiplos processos, como a maioria dos fenômenos psicológicos sociais (Mackie, Hamilton, Susskind \& Rosselli, 1996; Pereira, 2002). Os autores Mackie et al. (1996) sugerem que os estereótipos podem ser formados pelos processos cognitivo, afetivo, sociomotivacional e cultural, que agem no ambiente social e que podem sofrer influência de cada um desses processos, individualmente ou de forma combinada. Para Stangor (2000), a combinação dessas influências faz com que os estereótipos se confirmem facilmente e se tornem resistentes a mudanças.

Para Pereira (2002), os estereótipos são produtos da interação social, transmitidos de geração em geração, por meio de contatos diretos entre os diversos agentes sociais, bem como pelos meios de comunicação, que criam e reforçam esses estereótipos, sendo capazes de modificar as impressões sobre os grupos em vários sentidos.

\subsection{Desenvolvimento dos estereótipos}

A representação de informações sobre um grupo social dentro de memória pode ocorrer sobre três abordagens (Wells, 2010): os esquemas de grupos, protótipos e modelos baseados em exemplares. De acordo com Stangor e Schaller (1996), cada abordagem apresenta diferentes hipóteses sobre como as crenças do grupo são representadas e se enquadra em um nível diferente de especificidade.

Os esquemas de grupo são estruturas de conhecimento abstratas que especificam os atributos definidores relevantes ou as características de um grupo social (Wells, 2010). Para Pereira (2002), um esquema de grupo significa o conjunto das crenças de alguém a respeito das características prováveis de membros de determinado grupo. "Reconhece-se que a existência de um esquema sobre um grupo social é suficiente para influenciar a percepção que se tem sobre os membros deste grupo." (Pereira, 2002, p. 110).

Esses esquemas são fáceis de assimilar, armazenar e ativar e, portanto, facilmente influenciam nos julgamentos dos outros indivíduos, permitindo inferências a respeito de informações indisponíveis e indicando "roteiros" comportamentais a serem usados, a depender da circunstância (Pereira, 2002; Stangor \& Schaller, 1996).

Nesse sentido, os esquemas permitem emitir prontamente uma análise do comportamento dos outros indivíduos; eles categorizam os sujeitos de forma mais ampla, pela generalização, portanto, tendem à falta de especificidade, desencorajando o observador a subclassificar as características deles. Por exemplo, observemos o esquema de um bibliotecário, como demonstrado na Figura 1. Quando pensamos nesse indivíduo, logo lhe atribuímos características generalizadas do grupo: normalmente do sexo feminino, meia idade, usa óculos e coque no cabelo, roupas conservadoras.

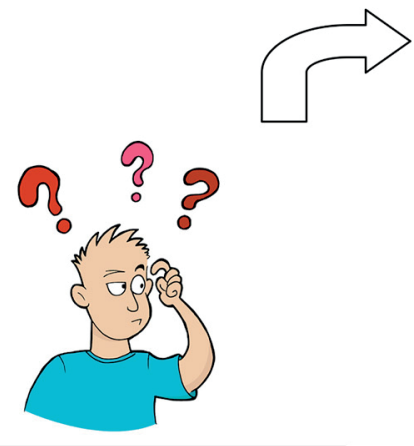

\section{Ele utiliza a categorização por meio de atributos definidores ou de características de um grupo social, já armazenados}

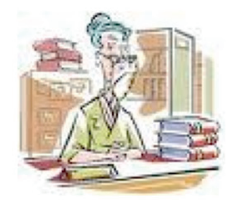

$\mathrm{O}$ indivíduo se depara com determinada situação

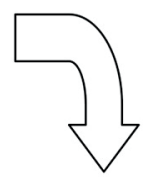

O esquema é ativado pela generalização, sem especificidade, sendo atribuídas ao indivíduo analisado aquelas características

Figura 1. Esquema de estereótipo do bibliotecário 
Hinton (2000) coloca que os esquemas facilitam a vida das pessoas. Sendo assim, quando alguém necessita de algum serviço prestado por esse profissional (bibliotecário), busca um indivíduo que se encaixe nesse esquema de estereótipo, muitas vezes resolvendo rapidamente o seu problema e com pouco esforço.

Outra abordagem trata dos estereótipos como protótipos. Esses são semelhantes aos esquemas do grupo, exceto por existirem em um nível mais baixo e mais específico de representação; eles estão ligados às propriedades ou às características mais importantes dos esquemas, fornecendo descrições detalhadas e específicas. Pereira (2002) define protótipo como uma representação abstrata das características típicas e, não, de todos os fatores de uma categoria. Para Stangor e Schaller (1996, p. 8), protótipos são "representações mentais que consistem de um conjunto de associações entre rótulos de grupo."

O protótipo é uma subcategoria de referência, na qual a combinação de características típicas cria a ideia de melhor exemplar de um grupo. Dessa forma, a ideia do protótipo permite ao sujeito, mediante a identificação das características típicas de várias categorias, a construção mental do melhor exemplar e, assim, quando ele encontrar um novo objeto, ele poderá compará-lo com o protótipo que tem armazenado na memória (Amoretti, 2001). Como exemplo, podemos citar o protótipo de uma cadeira. Quando se pensa em uma cadeira, atribuem-se algumas características a esse item, como a presença de um encosto, $o$ fato de não possuir braços e o fato de possuir quatro pés. Dessa forma, o protótipo de cadeira pode permitir que novos objetos possam ser identificados e classificados como cadeira, baseados na ideia do signo cadeira (Amoretti, 2001). Assim, quando o indivíduo for exposto a algo semelhante a uma cadeira, ele acionará o protótipo existente, o melhor exemplar de uma cadeira. A Figura 2 demonstra o protótipo de uma cadeira.

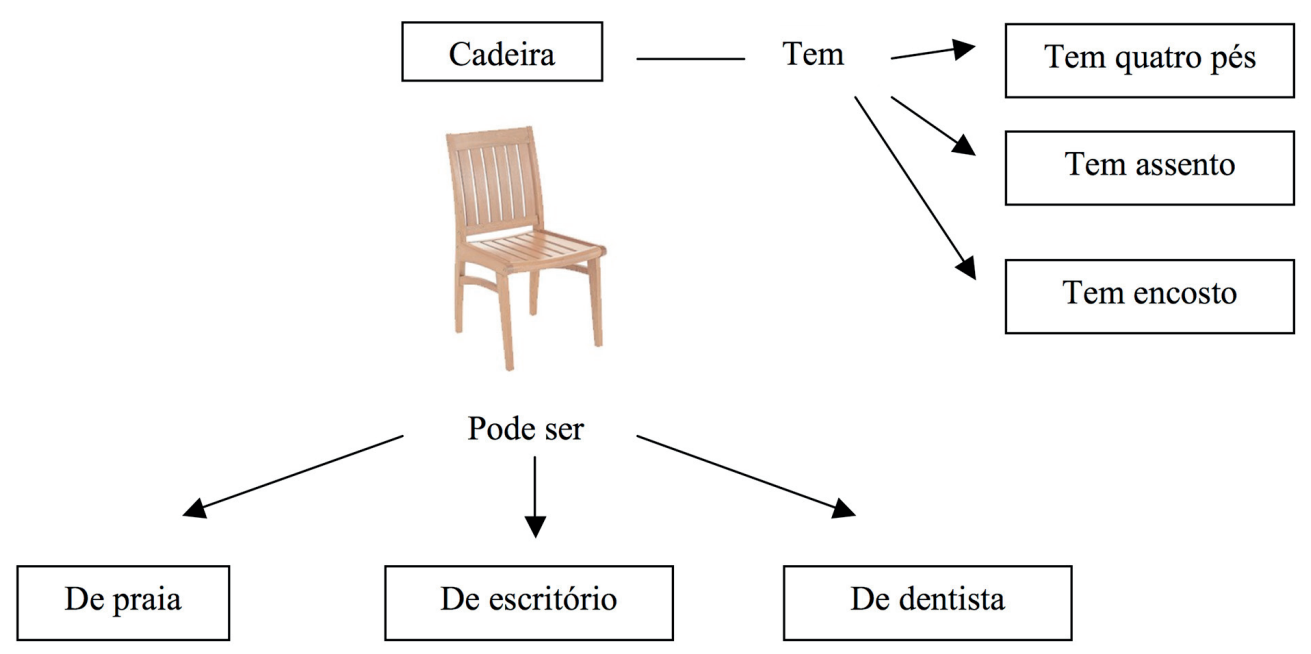

Figura 2. Protótipo de uma cadeira

Fonte: Adaptado de Amoretti (2001)

A terceira e última abordagem para a representação cognitiva de um grupo social se dá por meio do uso de modelos de exemplares. Além das representações abstratas dos grupos sociais, as pessoas também comprometem a memória com encontros específicos com os indivíduos.

Segundo essa ótica, a representação que se tem de pessoas reais pertencentes aos grupos estereotipados influencia o conteúdo do estereótipo (Pereira, 2002). Para o autor, os modelos abstratos - esquemas de grupo e protótipos - supõem a presença de um conjunto de representações de características típicas do objeto, sendo essas formadas nas experiências com exemplares do grupo ou na aprendizagem com agentes externos, como família, amigos, professores, mídia, enquanto os modelos baseados em exemplares supõem a existência de representações arquivadas na memória independentemente para cada um dos exemplares. Um exemplo seria quando somos solicitados a refletir sobre professores. A tendência, nesse exemplo, é evocar membros específicos dessa categoria, professores com os quais tivemos contato, levando em consideração as representações armazenadas na memória para concebermos o estereótipo do professor. 
Pereira (2002) dispõe que, no caso dos modelos baseados em exemplares, a percepção do estereótipo do objeto não ocorre por uma representação abstrata e, sim, por um conjunto de exemplares evocados por meio da mera exposição ao objeto. $\mathrm{O}$ autor acredita que esses modelos surgem como uma tentativa de lidar com fatores, como a diversificação dos subtipos encontrados nos grupos, a percepção da variabilidade grupal e a influência de variáveis contextuais para a aplicação dos estereótipos, o que não ocorre nos modelos abstratos. Stangor e Shaller (1996) acreditam que essa abordagem torna mais fácil o processo de representação da variabilidade intragrupal na memória.

Contudo, os autores mencionam que, mesmo na ausência de modelos exemplares, os estereótipos ainda podem ocorrer.

\subsection{Estereótipo do contador}

Muitos estudos vêm sendo realizados para examinar a imagem pública dos contadores, descrevendo as percepções que as pessoas têm tanto desses profissionais quanto da Contabilidade, a partir de diferentes perspectivas. Dimnik e Felton (2006) apontam que o profissional da Contabilidade é o que mais tem se preocupado com a imagem pública nos últimos anos. Os autores colocam que, durante anos, os contadores têm agonizado com a imagem de uma pessoa chata, pouco atraente, forçados a se defender contra acusações de irrelevância, esforçando-se para reforçar sua reputação de competência e integridade, situação já alertada, muito antes, por Holland (1973), quando afirmou que a profissão contábil, mais do que qualquer outra, travava batalhas com os remanescentes de um estereótipo negativo poderoso.

Em relação à profissão, as percepções encontradas apontam que o trabalho do contador envolve atividades repetitivas, chatas, e, principalmente, ligadas a cálculos e a impostos (Miranda; Miranda \& Araújo, 2012).

Essas percepções negativas sobre o profissional da Contabilidade começaram a ser expostas com as alegações de Stacey (1958), de que o contador era retratado em romances e poesias de forma pouco lisonjeira. Estudos posteriores mantiveram o pressuposto de que o estereótipo do contador era negativo, sendo tratado como chato, submisso, despreparado, sem criatividade, desinteressante (Aranya, Meir \& Bar-Ilan, 1978; Beardlsee \& O'Dowd, 1962; Cobbs, 1976; Cory, 1992; DeCoster \& Rhode, 1971).

Mais de cinquenta anos depois, essas percepções parecem estar inalteradas (Friedman \& Lyne, 2001; Hooper, Kearins \& Wells, 2009; Parker, 2000). Enis (1998) refere que isso pode ser consequência das percepções da Contabilidade e dos contadores, por consistirem de um conjunto complexo de imagens técnicas e pessoais entrelaçadas, as quais diferem entre os grupos de observadores.

Para Bougen (1994), essa percepção negativa persiste devido à complexidade da imagem do contador, a qual é derivada da interdependência entre a Contabilidade e a escrita fiscal e a indefinição das características pessoais e de Contabilidade em si. O autor ainda sugere que, historicamente, os contadores estiveram dispostos a aceitar a imagem negativa em relação à profissão, pois isso lhes permitiu maior credibilidade com o público. Para Brass (2004), os contadores são culpados dos equívocos do estereótipo negativo, já que nunca tentaram corrigir a imagem de escriturador fiscal.

Outro motivo alegado por vários autores é a falta de clareza, por parte do público, sobre o que é a profissão e quais são as atividades exercidas pelo profissional da Contabilidade (Cobbs, 1976; Hazell, 1998; Parker, 2000; Smith \& Briggs, 1999). McMurdy (1997). Acreditam esses autores que a linguagem utilizada por contadores é adotada como uma forma de confundir o público e mantê-lo no escuro sobre o que é Contabilidade.

Apesar de as mudanças no ambiente de negócios terem ocasionado uma transformação significativa no papel do contador (Albrecht \& Sack, 2000; Parker, 2000), essas percepções negativas continuam inalteradas (Baxter \& Kavanagh, 2012; Evans \& Fraser, 2012; Parker, 2000). A sombra do estereótipo do contador ainda permanece terrivelmente sobre a consciência pública (Jeacle, 2008). 
Por outro lado, há também estudos que sugerem a existência de alguns aspectos positivos na imagem dos contadores, apresentando características como honesto, confiável, preciso (Azevedo \& Cornachione Júnior, 2012; Bougen, 1994; Carnegei \& Napier, 2010; Coutinho e Silva \& Silva, 2012; Friedman \& Lyne, 2001; Felton; Dimnik \& Bay, 2007; Jeacle, 2008; Leal, Miranda, Araújo \& Borges, 2012).

Contudo, os diversos estudos citados sugerem que é impossível catalogar a imagem dos contabilistas de forma simples, em positiva ou em negativa, não alcançando, de fato, apenas um estereótipo da profissão (Dimnik \& Felton, 2006). Os autores colocam que os estereótipos do contador podem variar de acordo com o grupo que é inquirido para expressar opinião.

Para Carnigie e Napier (2010), uma compreensão das imagens externas dos contadores é importante para o julgamento dos papéis desses em um contexto social mais amplo. Azevedo (2010, p. 24) argumenta que "a profissão contábil carece de projetar uma imagem de confiança, respeitabilidade e de oferecer desafios, recompensas e perspectivas, a fim de atrair e reter os estudantes e profissionais mais talentosos e competentes". Para os jovens, a reputação de uma profissão como maçante e chata, é um forte desincentivo para seguir essa carreira, principalmente para os melhores alunos (Friedman \& Lyne, 2001). O que, de fato, reforça a ideia de que a percepção dos estudantes detém sobre um determinado curso é fator preponderante na escolha de suas carreiras profissionais (Azevedo, Cornachione Júnior \& Casa Nova, 2008).

\section{Metodologia da Pesquisa}

Essa pesquisa é classificada quanto aos objetivos como pesquisa descritiva, em que "pretende descrever com exatidão os fatos e fenômenos de determinada realidade" (Triviños, 2006, p. 110). Quanto ao delineamento da pesquisa, é do tipo levantamento ou survey. Para Gil (1999), as pesquisas do tipo levantamento caracterizam-se pela interrogação direta das pessoas cujo comportamento se almeja conhecer. No que se refere à abordagem do problema, a pesquisa é de natureza qualitativa, pois envolve examinar e refletir sobre as percepções da imagem da atividade do profissional da Contabilidade por parte de alunos e professores universitários. Para Richardson (1999), a abordagem qualitativa busca interpretar as características que adjetivam o objeto estudado. A população objeto da pesquisa compreende os estudantes e professores dos cursos de graduação de Contabilidade, Administração, Direito, Jornalismo e Engenharia de Produção de duas universidades (uma pública e uma particular) localizadas no Vale do Itajaí, Estado de Santa Catarina. A amostra da pesquisa foi composta por 461 estudantes e 102 professores. A escolha dos cursos foi por acessibilidade e retorno das respostas. Foram selecionados os últimos 2 períodos de cada curso. Essa escolha foi em função de que os alunos estariam mais familiarizados com o seu curso, com o perfil profissional e muitos já estariam atuando no mercado de trabalho, portanto, teriam mais condições de opinar sobre características de outra profissão. A coleta de dados foi realizada por meio de aplicação de questionário, sendo analisadas por intermédio da técnica de análise de conteúdo, a qual foi iniciada a partir da leitura das respostas. Ao longo desse processo, foram selecionados os temas ou unidades de análise, considerados mais relevantes para a pesquisa, os quais serviram de base para a fase de categorização, tendo sido criadas três categorias temáticas: o profissional, as atividades desempenhadas e o objetivo dessas atividades. 


\section{Análise dos Resultados}

A Tabela 1 apresenta as categorias de análise e respectivas subcategorias em relação à questão "O que você acha que o contador faz na sua atividade profissional?”.

Tabela 1

\section{Categorias e subcategorias da análise de conteúdo atribuições do contador}

\begin{tabular}{lll}
\hline Categoria Profissional & Categoria Atividades Executadas & Categoria Objetivos \\
\hline - Preciso e focado. & - Planejamento, execução e controle de atividades. & • Gerar informações \\
- Consultor de pessoas físicas e & - Auditoria e perícia contábil. & para a tomada de \\
jurídicas. & - Elaboração e análise de demonstrações financeiras. & decisões. \\
- Pessoa que cuida da organização. & - Controle de contas e finanças. & - Gerir a organização. \\
- Orienta pessoas e empresas & - Atendimento da legislação/fisco. & - Facilitar a fiscalização \\
- Auxilia na administração. & - Elaboração de folha de pagamento. & do governo. \\
- Organiza a atividade contábil. & - Declaração de IR. & - Alertar as empresas \\
- Grande administrador, parceiro & - Rotinas administrativas. & sobre as mudanças \\
na gestão do negócio. & - Calcula e apura impostos. & no mercado. \\
& - Análise de custos. & Solucionar \\
& - Constituição e baixa de empresas. & problemas. \\
& - Cálculos. & \\
\hline
\end{tabular}

Considerando os conteúdos relacionados ao profissional em si, os relatos apontam que prevaleceram os pensamentos de que o contador é um profissional que presta algum tipo de consultoria, seja financeira, tributária, administrativa. Ele também está relacionado a uma pessoa que orienta seus clientes, auxilia na administração do negócio: "Ele verifica possíveis erros e orienta qual a melhor solução com relação aos recursos humanos, fisco, impostos e afins", "O contador não é só uma obrigação e, sim, um parceiro na gestão financeira do negócio".

Em relação às atividades executadas, foram apontadas, principalmente, as funções ligadas à apuração de impostos, cumprimento da legislação, elaboração de balanços e demonstrações de resultado, bem como elaboração de folha de pagamento e declaração de imposto de renda: "Responsável pela parte contábil, fiscal, tributária e trabalhista de uma empresa"; "Lida com questões tributárias", "É responsável por toda a parte de finanças, desde folha de pagamento, até impostos, lucros e, também, investimentos"; "Várias funções, mas a primeira é a declaração de imposto de renda", "Agiliza os impostos das empresas", "Toda atividade financeira relacionada à demissão e admissão de pessoas em uma empresa", "Balanços patrimoniais, DRE, contratos sociais e alteração dos mesmos, guia de pagamento de impostos". Como se percebe, basicamente as atividades mencionadas foram aquelas relacionadas aos aspectos tributários, financeiros e às obrigações trabalhistas. Contudo, muitos respondentes mencionaram que o contador executa muitas atividades, envolvendo cálculos, números e também rotinas administrativas.

"Contas de empresas, auxílio na parte financeira e bastante uso de números"; "Trabalha com números e a integridade e legalidade deles numa empresa ou para pessoas físicas e jurídicas"; "Faz contas e números"; "Faz cálculos para realização de negócios em diversas áreas da sociedade"; "Cuida das contas de empresa a que presta serviços"; "Analisa e trabalha com números e cálculos"; "Trabalha com questões relacionadas à parte administrativa da empresa e/ou pessoa física”. Esse resultado não difere de outras pesquisas realizadas, o que vem a confirmar a presença de um imaginário coletivo sobre a Contabilidade, como evidenciado no trabalho de Dias e Martins (2005), segundo o qual a profissão do contador é vista como envolvendo cálculos e matemática e é voltada apenas para os números. Na pesquisa de Hunt, Falgiani e Intrieri (2004), os estudantes identificam a Contabilidade com a matemática podendo ter muitos cálculos. Jackeling, DeLange e Phillips (2010) também evidenciaram que os alunos percebem o contador envolvido com números, mesmo resultado encontrado por Wells, Kearins e Hooper (2009), o que demonstra a falta de conhecimento das pessoas sobre o que é a contabilidade. 
Outras descrições das atividades executadas pelo contador foram elencadas: "Destrói a vida de nós, empresários. Sei que não são todos, porém é, sem dúvida, a grande maioria que não faz a mínima ideia do que está acontecendo ao seu redor, não se atualiza e perde oportunidades a todo o momento"; "Faz praticamente a mesma coisa dia apos dia"; "Lida com números, cumpre normas, possui uma vida fria, tediante, usa quase somente a lógica e raciocínio prático, esquece-se das pessoas e de outros fatores sociais"; "Poderia realizar trabalhos pensando num todo, tendo uma visão geral dos negócios e não somente fechados em atender a questões operacionais".

São notáveis as críticas ao contador, em relação à falta de algumas habilidades pessoais, como senso crítico, proatividade, saber lidar com pessoas. Isso pode, de certa maneira, estar atrelado à formação técnica desse profissional, denunciando que a educação na área de Contabilidade está ainda presa à memorização de conhecimentos e domínio de conteúdos em detrimento do desenvolvimento de habilidades e atitudes dos estudantes (Albrecht \& Sack, 2000). E, também, pela influência exercida pelos meios de comunicação, que transmitem a imagem do contador como tímido, introvertido, monótono, chato, de visão limitada, lógico, sem criatividade, introspectivo, que não gosta de lidar com pessoas, antissocial (Dimnik \& Felton, 2006; Michael \& Levas, 2003; Smith \& Briggs, 1999; Smith \& Jacobs, 2011).

Quanto aos objetivos das atividades executadas pelo contador, foram apontados desde facilitar o fisco, gerir a empresa, gerar informações para a tomada de decisões a alertar sobre as mudanças no mercado, zelar pelo bem da organização: "Faz cálculos e administra bens de terceiros para que facilite para o fisco"; "Orienta e zela pelo bem das organizações e das pessoas"; "Controla as empresas, orientando-as a seguirem um caminho certo dentro das normas e leis"; "Estrutura as informações financeiras com o objetivo de orientar a tomada de decisão"; "Soluciona problemas".

De forma geral, a visão da atividade do contador ainda está atrelada ao contador tradicional, que é responsável pela escrituração contábil, entrega de declarações, apuração de impostos, contudo, é uma visão muito restrita, o que demonstra que a maior parte dos respondentes não tem uma ideia clara dessa profissão e nem da própria Contabilidade. Outras pesquisas também demonstram que há essa falta de entendimento sobre o que é a profissão e a Contabilidade (Dias \& Martins, 2005; Malthus \& Fowler, 2009; Miranda, Miranda \& Araújo, 2012; Pekdemir \& Pekdemir; 2010).

A segunda pergunta aberta foi direcionada apenas para os alunos e professores do curso de Contabilidade. No caso dos professores, procurou-se saber como eles imaginam que os contadores são percebidos por outros profissionais. As respostas foram divididas em duas categorias: visão da profissão e visão do profissional. A Tabela 2 apresenta as categorias e subcategorias identificadas.

Tabela 2

\section{Categorias e subcategorias da análise de conteúdo na visão da carreira do contador}

\begin{tabular}{ll}
\hline Categoria Visão da Profissão & Categoria Visão do Profissional \\
\hline Falta valorização. & Falta formação. \\
Envolve cálculos, tributos e análises financeiras. & Agentes da burocracia. \\
Respeitada e admirada. & Pouco crítico. \\
Consultores no ponto de vista de números. & Metódico. \\
Importante. & Pouco comunicativo. \\
Atividades repetitivas. & Introspectivo. \\
Cumpre normas e regras. & Matemático. \\
\hline
\end{tabular}

Muitos professores de Contabilidade acreditam que a maior parte das pessoas não conhece esta profissão e, por isso, consideram a carreira como pouco valorizada, envolvendo muitos cálculos, e que os contadores são agentes da burocracia. Outros alegam que é uma carreira importante, respeitada e admirada. Alguns depoimentos exemplificam essa análise: "Aqueles que têm pouco conhecimento sobre Contabilidade nos tratam apenas como profissionais que executam atividades repetitivas e que cumprem a legislação, afirmando que a Contabilidade não serve para nada; os que não conhecem Contabilidade acreditam que somos engenheiros (muitos cálculos) e, por isso mesmo, não dão importância ao trabalho 
executado pela classe contábil"; "Uma parte dos contadores são vistos como profissionais conformados, sem iniciativa e sérios. Contudo, existem profissionais que são participativos, inovadores e que se comprometem com a profissão, aqueles que fazem a diferença"; "Profissionais fechados em si mesmos e que têm dificuldades para comunicar-se com outras áreas"; "Matemáticos ou de ciências exatas, sem grande relevância e burocratas"; "Mero apurador de impostos".

Pergunta semelhante foi feita aos alunos de Contabilidade: "Qual a reação das pessoas quando você comenta que cursa Contabilidade? O que elas dizem?”. A análise das respostas permitiu a criação de 3 categorias: visão do curso, escolha do curso e visão da futura carreira.

Na categoria "visão do curso", muitos responderam que as pessoas acham um curso chato, que envolve muita matemática, complexo, difícil. Mas também pode ser considerado um curso com grandes possibilidades de atuação, boa empregabilidade, curso interessante completo: "Acreditam que é uma ciência exata e pensam que sou ótimo em matemática"; "Você gosta de matemática? A grande maioria não sabe exatamente o que o contador faz, não gosta sem saber e se espanta por saber que você faz Contabilidade e que gosta". Na categoria escolha do curso, foi mencionado que é um curso com grandes possibilidades, empregabilidade, contudo com menor remuneração que outros e que as pessoas que escolhem Contabilidade são "loucas" e gostam muito de números: "Grandes chances profissionais"; "Curso com boa empregabilidade, especialmente na área pública"; "Profissão boa, com emprego garantido. Mercado precisando de contadores. Possibilidade de boa remuneração"; "Que estou louca e que gosto de muita matemática!".

Em relação à visão da carreira futura como contador, os alunos mencionaram que é uma boa profissão, profissional essencial para a sociedade e muito promissora: "Elogiam, dizem que é uma profissão boa, com mercado de trabalho atraente"; "Não costumam se impressionar muito. Geralmente dizem que tem um grande mercado de trabalho, porém já escutei pessoas falando que fariam Contabilidade agora, em vez de Administração ou Economia. Acredito que está sendo mais valorizado".

Como se percebe, permanece a representação do contador como uma carreira desinteressante, envolvendo atividades repetitivas, que cumpre normas e envolve muitos cálculos, além do que o profissional continua sendo visto como introspectivo, pouco crítico, pouco comunicativo.

\section{Considerações Finais}

Este estudo teve como objetivo geral identificar e analisar a percepção que estudantes e professores universitários têm acerca da profissão contábil.

Em relação às atividades que esse profissional exerce, as respostas foram classificadas em três categorias: "objetivo da profissão", "o profissional" e "as atividades propriamente ditas". Quanto à primeira categoria, as respostas indicam que o objetivo dessa profissão é gerar informações para a tomada de decisão, gerir a organização, solucionar problemas e facilitar a fiscalização do Governo. Já o profissional é considerado uma pessoa que orienta, auxilia na administração, organiza as atividades da empresa e é um parceiro da organização. E as atividades compreendem o controle de contas, atendimento da legislação, escrituração contábil, folha de pagamento, cálculos, apuração de impostos e declaração de imposto de renda.

A maior parte dos respondentes categorizou as atividades do contador de forma mais ampla, por meio de esquemas de grupo, os quais ocorrem pela generalização dos sujeitos e tendem à falta de especificidade. Exemplos dessas atividades são assim apontadas: controle de contas, cálculos, atendimento da legislação, solução de problemas, ou seja, não há um nível de categorização mais detalhado.

Outras respostas foram baseadas em protótipos, que fornecem descrições mais detalhadas sobre o grupo analisado, como é o caso das respostas envolvendo elaboração de escrituração contábil, folha de pagamento e apuração de impostos, observando-se que há uma subcategorização das atividades exercidas. Já o uso de modelos de exemplares, baseados na influência do contato real com o sujeito estereotipado e o conteúdo do estereótipo, foi evidenciado nas respostas em que o contador é visto como meio de facilitar a vida do fisco, ou um grande parceiro da organização. Isso demonstra que os respondentes que tiveram 
contato com esse profissional levaram em consideração essas representações armazenadas na memória, de acordo com suas experiências.

Contudo, esse panorama não difere do que algumas pesquisas já relataram, ou seja, é evidente a falta de clareza sobre as atividades e sobre a própria profissão apresentadas pelos indivíduos pesquisados (Hazell, 1998; Parker, 2000; Smith \& Briggs, 1999) e a indefinição das características pessoais e da Contabilidade em si (Bougen, 1994). Há uma confusão em separar o que é atividade, profissional e Contabilidade por parte da sociedade. As opiniões sobre o contador e a Contabilidade são expressas de maneira que nem sempre conferem com o papel do contador ou da própria atividade (Dias \& Martins, 2005). Entre as atribuições designadas pelas pessoas, em geral, muitas nem pertencem aos contadores, como é o caso de controle de contas financeiras, ou organização administrativa da empresa, o que demonstra que elas não conhecem as verdadeiras atribuições de um contador, ou o que realmente é Contabilidade. A profissão normalmente está relacionada a situações triviais e a de encontrar pessoas que resolvam necessidades imediatas, como a apresentação de declaração de Imposto de Renda.

Quando questionados sobre a forma que outros profissionais percebiam a profissão do contador, os professores de Contabilidade afirmam que essa imagem não é boa. Eles acreditam que o contador é visto como um profissional sem visão de negócios, pouco participativo ou envolvido na gestão; pouco atualizado; usa muito a lógica e se esquece das pessoas; apenas cumpre normas; e resolve questões operacionais. Quanto à profissão em si, esta é percebida envolvendo cálculos e matemática; ligada a aspectos fiscais e tributários, principalmente à declaração do Imposto de Renda.

Os estudantes de Contabilidade, por sua vez, quando questionados sobre a reação das pessoas quando sabiam que ele cursava Contabilidade, responderam que o curso é visto como chato, complexo, envolve muita matemática, mas que apresenta grandes possibilidades de atuação, empregabilidade, embora com menor remuneração que outros cursos e precisa ser um pouco louco e gostar muito de números. A visão da futura carreira foi retratada como uma boa profissão, essencial para a sociedade e muito promissora.

Como se pode notar, tanto as opiniões declaradas pelos professores quanto pelos estudantes confirmam a permanência da representação do contador como uma carreira desinteressante, envolvendo atividades repetitivas, que cumpre normas e envolve muitos cálculos, além do que o próprio profissional vem sendo visto como introspectivo, pouco crítico e pouco comunicativo. As consequências dessa imagem para essa profissão é a profecia do autorrealizável, segundo a qual os indivíduos acabam se comportando de maneira a seguir a crença originalmente estereotipada, e assim confirmando o estereótipo existente (Wells, 2010). Esse fato já foi evidenciado em vários estudos (Azevedo, 2010; Steele \& Aronson, 1995; Wells, 2010), sendo que, para Pereira (2002), essas profecias contribuem de forma decisiva para a manutenção dos estereótipos.

De forma geral, o que se pode concluir é que ainda paira no ar o estereótipo do beancounter, a imagem do contador tradicional ainda está muito ligada à do contador contemporâneo. As características de uma profissão chata, maçante, rotineira, que envolve muitos cálculos, sem criatividade, sem habilidades com pessoas, permanecem.

E como modificar essa situação? Para Pereira (2002), o processo de mudança de um estereótipo é muito lento e trabalhoso; requer um alto grau de motivação e dispêndio de uma representativa parcela de esforços por parte do percebedor. Para que ocorra alguma mudança, esse profissional deve procurar sua importância e agregar valor à sua profissão. O profissional da Contabilidade deve se empenhar em demonstrar a importância do seu trabalho e das atividades que realiza, a fim de que a sociedade tenha noção e nitidez das funções atreladas a ele e as considere relevantes. Com a compreensão das funções do contador, a dimensão e a amplitude da profissão se tornam mais claras, o que favorece positivamente a imagem pública. Vale lembrar que o valor da profissão, assim como a sua credibilidade e seu desenvolvimento futuro, estão diretamente ligados a essa imagem.

Faz-se necessário maior envolvimento dos contadores e dos próprios órgãos de classe, para aproximar mais a Contabilidade das pessoas, demonstrando, assim, também, o seu papel de agente social. É imperativo que os contadores se posicionem como uma categoria profissional importante para o desenvolvimento da sociedade, estando cada vez mais presente e ativa no contexto econômico, social e político. 
As Instituições de Ensino Superior (IES) também possuem papel fundamental para a mudança da imagem do contador e, por isso, devem proporcionar, além da formação técnica desse futuro profissional, o desenvolvimento de habilidades interpessoais, de comunicação e de gestão, habilidades essas tão solicitadas pelo mercado e pela própria sociedade.

\section{Referências}

Albrecht, W. S. \& Sack, R. J. (2000). Accounting education: Charting the course through a perilous future. American Education Association Series, 16.

Albu, N.; Albu, C. N. \& Girbina, M. M. (2011). Can the stereotype of accountant be changed through accounting education? Some conjectures on educating accounting students in Romania. International Journal of Business Research Publisher, 11 (1), p. 156-163.

Amoretti, M. S. M. (2001). Protótipos e estereótipos: aprendizagem de conceitos mapas conceituais: experiência em educação a distância. Informática na educação: teoria e prática, 4(2), p. 49-55.

Aranya, N., Meir, E. I. \& Bar-Ilan, A. (1978). An empirical examination of the stereotype accountant based on Holland's theory. Journal of Occupational Psychology, 51(2), p. 139-145.

Azevedo, R. F. L. (2010). A percepção pública sobre os contadores: "Bem ou mal na foto"? 2010. 115 f. Dissertação de mestrado em Contabilidade. Universidade de São Paulo, Faculdade de Economia, Administração e Contabilidade, São Paulo, SP, Brasil.

Azevedo, R. F. L.; Cornachione Júnior, E. B. \& Casa Nova, S. P. (2008). A percepção dos estudantes sobre o curso e o perfil dos estudantes de contabilidade: uma análise comparativa das percepções e estereotipagem. Anais do Congresso USP de Contabilidade e Controladoria, São Paulo, SP, Brasil, 8.

Azevedo, R. F. L. \& Cornachione Júnior, E. B. (2012). Ética profissional contábil: uma análise visual da percepção pública. Revista de Educação e Pesquisa em Contabilidade - Repec, 6(1), p. 19-37.

Baxter, P. \& Kavanagh, M. (2012). Stereotypes, students' perceptions and inherent creativity: further Australian evidence. Australasian Accounting Business and Finance Journal, 6(5), p. 81-100.

Belski, W. H., Richmond, K. A. \& Brozovsky, J. A. (2004). “A Few Bad Apples in the Bunch?”: A Post-Enron Examination of the Business Student's Perception of the Prestige of the Accounting Profession. New Accountant, (718), p. 12-15.

Beardlsee, D. C. \& O'Dowd, D. D. (1962). Students and the occupational world. In: Sandford, N.; Adellson, J. (Eds). The American College: A psychological and social interpretation of higher learning. New York: Wiley.

Bougen, P. D. (1994). Joking apart: The serious side to the accountant stereotype. Accounting, Organizations and Society, 3(19), p. 319-335.

Brass, R. (2004). Is image letting accountants down? Accounting \& Business, 8(1), p. 20-22.

Carnegie, G. D. \& Napier, C. J. (2010). Traditional accountants and business professionals: portraying the accounting profession after Enron. Accounting Organizations and Society, 3(35), p. 360-376.

Cobbs, J. L. (1976). How the business press views the accounting profession. Journal of Accountancy, 142(3), p. 94-97.

Cory, S. N. (1992). Quality and quantity of accounting students and the stereotypical accountant: Is there a relationship? Journal of Accounting Education, 10(1), p. 1-24.

Coutinho e Silva, A. H., \& Silva, É. G. R. D. (2012, March). Percepção dos Estudantes de Ciências Contábeis do Rio de Janeiro sobre o estereótipo do profissional de Contabilidade no período após a adoção do IFRS. In III Congresso Nacional de Administração e Ciências Contábeis-AdCont 2012. 
DeCoster, D. T. \& Rhode, J. G. (1971). The accountant's stereotype: real or imagined, deserved or unwarranted. Accounting Review, 46(4), p. 651-669.

Dimnik, T. \& Felton, S. (2006). Accountant stereotypes in movies distributed in North America in the twentieth century. Accounting Organizations and Society, 31(2), p. 129-155.

Dias, G. M. \& Martins, G. A. (2005). Representações sociais e imaginário coletivo na contabilidade. Revista Contemporânea de Contabilidade, 2(4), p. 9-31.

Enis, C. R. (1998). The effect of gender on role perceptions of accountants: Twenty years through the looking glass. Advances in Public Interest Accounting, 7, p. 107-138.

Evans, L, \& Fraser, I. (2012). The accountant's social background and stereotype in popular culture: the novels of Alexander Clark Smith. Accounting, Auditing \& Accountability Journal, 25(6), p. 964-1000.

Felton, S., Dimnik, T. \& Bay, D. (2007). Perceptions of accountant's ethics: evidence from their portrayal in cinema. Journal of Business Ethics, 83(2), p. 217-232.

Fisher, R. \& Murphy, V. (1995). A pariah profession? Some student perceptions of accounting and accountancy. Studies in Higher Education, 20(1), p. 45-58.

Friedman, A. L. \& Lyne, S. R. (2001). The beancounter stereotype: towards a general model of stereotype generation. Critical Perspectives on Accounting, 12(4), p. 423-451.

Gil, A. C. (1999). Métodos e técnicas de pesquisa social. 5. ed. São Paulo: Atlas.

Hamilton, D. \& Trolier, T. K. (1986). Stereotypes and stereotyping: an overview of cognitive approach. In: Dovidio, J. F.; Gaertner, S. L. (Coord.). Prejudice, discrimination, and racism. Orlando: Academic Press.

Hazell, M. (1998). Would you like your child to become an accountant? Management Accounting, 76(11), p. 56.

Hinton, P. R. (2000). Stereotypes, cognition and culture. Hove: Psychology Press.

Hiroshi, S. (1998). Um plano de marketing para a contabilidade. Caderno de Estudos, 10(17), p. 47-58.

Holland, J. L. (1973). The Psychology of Vocational Choice. Englewood Cliffs, New Jersey: Prentice Hall.

Hooper, K.; Kearins, K. \& Wells, P. (2009). Tax agent, bean counter or cost controller: what do clients think of their accountants. Anais da Afaanz Conference, 2009, Adelaide, South Australia, Australia.

Hunt, S. C.; Falgiani, A. A. \& Intrieri, R. C. (2004). The nature and origins of student's perceptions of accountants. Journal of Education for Business, 79(3), p. 142-148.

Imada, A. S.; Fletcher, C. \& Dalessio, A. (1980). Individual correlates of an occupational stereotype: a reexamination of the stereotype of accountants. Journal of Applied Psychology, 65(4), p. 436-439.

Jackling, B.; DeLange, P. \& Phillips, J. (2010). Perceptions of accounting: do australian born students see accounting differently from those born overseas? In: Moroney, R.; Delange, P. (Ed.). Proceedings of the 2010 Accounting \& Finance Association of Australia and New Zealand (Afaanz) Conference, Carlton, Melbourne, p. 1-25.

Jeacle, L. (2008). Beyond the boring grey: the construction of the colourful accountant. Critical Perspectives on Accounting, 19(8), p. 1296-1320.

Leyens, J. P.; Yzerbyt, V. \& Schadron, G. (1994). Stereotypes and social cognition. London: Sage.

Leal, E. A., Miranda, G. J., Araújo, T. S. \& Borges, L. F. M. (2012). Estereótipos na profissão contábil. Anais do Encontro da Associação Nacional de Pós-graduação e Pesquisa em Administração - ENANPAD, Rio de Janeiro, RJ, Brasil, 36.

Lippmann, W. (1922). Public opinion. New York: Harcourt, Brace.

Malthus, S. \& Fowler, C. (2008). Perceptions of accounting as a carrer: a qualitative New Zeland study. Anais da Afaanz Conference, New Zealand. 
Macrae, C. N.; Milne, A. \& Bodenhausen, G. (1994). Stereotypes as energy-saving devices: a peek inside the cognitive toolbox. Journal of Experimental Social Psychology, 66(1), p. 37-47.

Mackie, D. M., Hamilton, D. L., Susskind, J. \& Rosselli, F. (1996). Social Psychological Foundations of Stereotype Formation. In: Macrae, C. N.; Stangor, C.; Hewstone, M. (Eds.), Stereotypes and Stereotyping. New York: Guilford Press.

Maximiano, A. C. A. (2004). Teoria geral da administração: da revolução urbana à revolução digital. 4. ed. São Paulo: Atlas.

McMurdy, D. (1997). Down with goobledygook. CA Magazine, 130(7), p. 13.

Michaels, N. M. \& Levas, M. G. (2003). The relationship of personality traits and self-monitoring behavior to choice of business major. Journal of Education for Business, 78(3), p.153-157.

Miranda, C. S.; Mir anda, R. A. M. \& Araujo, A. M. P. (2012). Percepções dos estudantes do ensino médio sobre o curso de ciências contábeis e as atividades do professional contador. Anais do Encontro da Associação Nacional dos Programas de Pós-graduação em Ciências Contábeis, CD-ROM, Florianópolis. SC, Brasil, 6 .

Morais, J. J. S. (2007). A representação social do contador e a imagem dele perante a sociedade. Studia Diversa, CCAE-UFPB, 1(1), p. 36-43.

Myers, D. G. (2000). Social psychology. Boston: McGraw-Hill.

Parker, L. (2000). Goodbye, number cruncher! Australian CPA, 77(2), p. 50-52.

Pereira, E. P. (2002). Psicologia social dos estereótipos. Sao Paulo: E.P.U.

Pekdemir, I. \& Pekdemir, R. (2013). High school teachers' perceptions and opinions on professional accountants: the Turkey case. Recuperado em 15 julho, 2013, de http://ideas.repec.org/p/pra/mpra$\mathrm{pa} / 29865 . \mathrm{html}$.

Richardson, R. J. (1999). Pesquisa social: métodos e técnicas. 3. ed. São Paulo: Atlas.

Robbins, S. P. (2005). Comportamento organizacional. São Paulo: Pearson Prentice Hall.

Schlee, R., Curren, M. T., Harich, K. R. \& Kiesler, T. (2007). Perception bias among undergraduate business students by major. Journal of Education for Business, 82(3), p. 169-177.

Smith, M. \& Briggs, S. (1999). From beancounter to action hero. Charter, 70(1), p. 36-39.

Smith, D. \& Jacobs, K. (2011) "Breaking up the sky": the characterisation of accounting and accountants in popular music. Accounting, Auditing \& Accountability Journal, 24(7), p. 904-931.

Stacey, N. A. H. (1958). The accountant in literature. Accounting Review, 33(1), p. 102-105.

Stangor, C. (2000). Volume overview. In: STANGOR, C. (Ed.). Stereotypes and Prejudice. Philadelphia: Psycology Press.

Stangor, C. \& Schaller, M. (1996). Stereotypes as individual and collective representations. In: Macrae, C., Stangor, C.; Hewstone, M. (Eds.), Stereotypes and stereotyping. p. 3-37. New York: Guilford Press.

Steele, C. M. \& Aronson, J. (1995). Stereotype threat and the intellectual test performance of African Americans. Journal of Personality and Social Psychology, 69(5), p. 797-811.

Tajfel, H. \& Turner, J. C. (1986).The social identitfy theory of intergroup behaviour. In: Worchel, S.; Austin, W. G. (Eds.). Psychology of intergroup relations. Chicago, MI: Nelson Hall.

Trivños, A. N. S. (2006). Introdução à pesquisa em ciências sociais: a pesquisa qualitativa em educação. São Paulo: Atlas. 
Vicente, C. C. S. \& Machado, M. J. (2010). A imagem dos contabilistas: diferenças e factores que as determinam. Conferência: Innovación y responsabilidad: desafios y soluciones, Encuentro AECA - Asociación Española de Contabilitad y Administración de Empresas, Coimbra - Portugal, 14.

Wells, P. K. (2010). Those persistent accounting stereotypes: why are they so resistant to change? Anais da Afaanz Conference, New Zealand.

Wells, P. K.; Kearins, K. \& Hooper, K. (2009). Perceptions of accounting and accountants: looking in the mirror. Anais da American Accounting Association - AAA, New York. 